\title{
Binge Drinking and TMT: Evaluating Responses to Anti-Binge Drinking PSAs from a Terror Management Theory Perspective
}

\author{
Norman C. H. Wong ${ }^{1} \&$ Stephanie Schartel Dunn ${ }^{1}$ \\ ${ }^{1}$ Department of Communication, University of Oklahoma \\ Correspondence: Dr. Norman C. H. Wong, Department of Communication, 610 Elm Avenue, University of \\ Oklahoma, Norman, Oklahoma 73019, USA. Tel: 1-405-325-3754. E-mail: nwong@ou.edu
}

Received: September 7, 2013 Accepted: September 21, 2013 Available online: October 10, 2013

doi:10.11114/smc.v1i2.216

URL: http://dx.doi.org/10.11114/smc.v1i2.216

\begin{abstract}
An experiment was conducted with 264 college students whose self-esteem were highly linked or not to their binge drinking behaviors (i.e., high binge drinking-based self esteem or low binge drinking-based self-esteem). Participants were exposed to a mortality-salient/non-mortality-salient anti-binge drinking public service announcement (PSA), or a control ad. Cognitive and emotional responses to the ads were assessed. Results found an interaction between binge drinking-based self-esteem and mortality-saliency of the ad. Those with high binge drinking-based self-esteem reported significantly lower intentions to not binge drink, more negative evaluation of the ads, greater message avoidance, and more positive binge drinking attitudes in response to the mortality-salient PSAs compared to those exposed to non-mortality-salient PSAs, and those with low binge drinking-based self-esteem. Additionally, response costs associated with not binge drinking was tested within the EPPM framework and found to have an impact. Implications of the results for anti-binge drinking campaigns are discussed along with future research directions.
\end{abstract}

Keywords: Terror management theory, binge drinking, PSAs

\section{Introduction}

The Centers for Disease Control and Prevention (CDC) recently released a report that estimated more than 38 million adults binge drink an average of four times a month, with binge drinking most common among young adults between 18 and 34 (CDC, 2012). Binge drinking is defined as consuming four or more drinks for women and five or more drinks for men on a single occasion within a 2-hour time frame (Wechsler et al., 2002; CDC, 2012). In particular, the most recent results from the National Survey of Drug Use and Health (SAMHSA, 2012) found that among those between the ages of 18 to 25,38 percent binged on alcohol in the past month. Consistent with this finding, in the most recent results from the Monitoring the Future Survey, 36\% of college students surveyed reported they had binged on alcohol in the past two weeks (Johnston, O'Malley, Bachman, \& Schulenberg, 2012). While this represents a decline in binge drinking from past years, it still poses a serious health concern among the college population. Efforts to curb alcohol misuse among this population have had limited success (Wolfson et al., 2012). Binge drinkers put themselves at risk for many health and social problems, including suffering from liver disease, certain cancers, heart disease, sexually transmitted diseases, unplanned pregnancies, and getting in trouble with the police (Wechsler et al., 2002). Moreover, they also put others at risk as annually, about 600,000 college students suffer unintentional alcohol-related injuries such as car accidents. Approximately 700,000 college students are assaulted by a peer who had been drinking, and 97,000 are the victims of alcohol-related sexual assault or rape (Hingson, Heeren, Winter, \& Wechsler, 2005).

To combat the problem of binge drinking on college campuses, several approaches have been used in an attempt to curb excessive alcohol consumption such as alcohol education programs, social norms campaigns, alcohol counter-marketing, motivational interviewing and implementation of campus-wide alcohol control policies (for a review, see Laramer \& Cronce, 2007; Paek \& Hove, 2012). Alcohol education programs are described as those that primarily focus on increasing students' awareness of the negative health consequences associated with alcohol abuse and binge drinking (Paek \& Hove, 2012). Social norms campaigns aim to correct misperceptions college students have regarding the prevalence (i.e., descriptive norms) of binge drinking on college campuses 
and the social acceptability (i.e., injunctive norms) of excessive alcohol consumption (Paek \& Hove, 2012). Alcohol counter-marketing involves efforts to promote alcohol education programs via the use of incentives and making them more easily accessible, as well as promotion of alcohol-free events (Paek \& Hove, 2012). Motivational interviewing interventions involve the use of a client-centered therapeutic style of interviewing to elicit motivation within the client to change his or her risky behaviors (Miller \& Rollnick, 2002). Specifically, motivational interviewers use a variety of interviewing techniques (e.g., asking open questions, affirming, listening reflectively, and summarizing) to facilitate clients' exploration of their ambivalence to change risky behaviors and increase change talk within an empathic and collaborative environment (Miller \& Rollnick, 2002). Lastly, the use of alcohol control policies focuses on the enforcement of laws restricting alcohol consumption on campus or at college events, and imposing sanctions for underage drinking and the use of fake identification to purchase alcohol (Paek \& Hove, 2012). In a test of the different approaches, it was found that the least effective was alcohol education programs (Paek \& Hove, 2012). This finding is consistent with previous studies on the effectiveness of alcohol education programs, with many finding little to no impact on reducing alcohol consumption (Larimer \& Cronce, 2007; Palmer, Kilmer, \& Larimer, 2006).

Similar to alcohol education programs, many mass-mediated anti-binge drinking campaigns use PSAs to highlight the health and social risks associated with excessive alcohol consumption (Treise, Wolburg, \& Otnes, 1999). One of the most prevalent types of messages found in PSAs is the use of threatening messages, or fear appeals (Treise et al., 1999). Unfortunately, there are mixed findings regarding the effectiveness of fear appeals in persuading people to not engage in risky unhealthy behaviors (Keller, 1999; Ruiter, Abraham, \& Kok, 2001). While some fear appeals work as intended to motivate individuals to reduce their risky behaviors, others seem to lead individuals to engage in increased levels of the risky behavior or hold positive attitudes toward the risky behavior (e.g., Arnett, 2000; Witte, 1994). This poses a serious concern for the use of fear-arousing messages in anti-binge drinking campaigns and it is important to understand situations where fear appeals work as well as situations where fear appeals fail to achieve the desired outcomes (Witte, 1992).

A common characteristic found in many fear appeals is the focus on mortality-salient risks associated with performing an unhealthy behavior. Many scholars recognize the lack of understanding there is concerning how fear appeals are cognitively processed and how they work in cooperation with other persuasive strategies (Witte, 1992; Roskos-Ewoldsen, Yu, \& Rhodes, 2004; Dillard \& Peck, 2001). Fear appeals can certainly be utilized to elicit mortality salience. Given this situation, Terror Management Theory (TMT) may offer some insights into why fear appeals are effective at motivating behavior change among some people but not others. In this paper, the relationship between TMT and fear appeals will be explored together within the context of examining college students' responses to anti-binge drinking PSAs that feature either mortality-salient or non-mortality-salient fear appeals.

The study is an extension of Jessop and Wade's (2008) previous research in this area by using a mediated message mortality-salience elicitation procedure. Scholars have typically relied on traditional mortality salience manipulations in the past through word searches, images, word completion tasks, and having participants think and write about their own death. However, in addition to using the traditional mortality-salience manipulation, Jessop and Wade (2008) found that they were also able to manipulate mortality salience through the use of simple textual messages that described the mortality-related risks associated with binge drinking. Compared to the control groups, those who received the binge drinking mortality-salience information reported higher levels of death-thoughts accessibility, comparable to the levels achieved via the use of traditional mortality salience manipulations (Jessop \& Wade, 2008). Also, recent studies indicate that mortality salience can be elicited through mediated messages as well (Fransen, Fennis, Pryun, \& Das, 2007). The present research therefore seeks to use a mass-mediated message (i.e., PSA) to elicit mortality salience as a further test of using new methods for manipulating mortality salience in TMT studies. A brief review of TMT and the fear appeals literature follows.

\section{Terror Management Theory}

Terror Management Theory (TMT) stems from the belief that every action an individual takes is motivated by their inherent desire to avoid death (Becker, 1973; Schmeichel, Gailliot, Filardo, McGregor, Gitter, \& Baumeister, 2009; Hayes, Schimel, Arndt, \& Faucher, 2010). Avoiding death is a natural, and generally unconscious instinct that supports self-preservation. Though death avoidance is an unconscious motivator, the desire to avoid death is so prevalent that death avoidance strategies are built into social norms (Hayes et al, 2010). Death anxiety has been found to increase the likelihood of the use of health-promoting behaviors, especially in younger adults (Bozo, Tunca, \& Simsek, 2009). Increased likelihood of engaging in health-promoting behaviors in response to death anxiety is logical, as healthy behaviors inspire self-preservation. Thus, it is expected that health messages that heighten an individual's death anxiety should lead them to reduce 
their intentions to enact risky health behaviors. One way in which death anxiety can be increased is by exposing individuals to mortality-salient messages.

Although using mortality-salient health messages may motivate some people to engage in health promoting behaviors or avoid risky unhealthy behaviors as a means of self-preservation, TMT posits that there may be other pathways to cope with death anxiety. One strategy is to increase self-esteem as a means of buffering against anxiety (Schmeichel et al, 2009). Fransen, Smeesters, and Fennis (2011) found that mortality salience appeals were less effective when individuals are surrounded by their peers because the presence of others enhanced their self-esteem. When individuals believe they are of worth to the world, they are less likely to dwell on death-related thoughts. TMT scholars identify maintaining high self-esteem as a buffer of death related-anxiety (Pyszczynski, Greenberg, Solomon, Arndt, \& Schimel, 2004). Specifically, high self-esteem acts as an anxiety buffer by helping individuals maintain a positive outlook on life, thereby allowing them to more easily cope with their anxieties in response to threats (Greenberg et al., 1997). Within the health domain, it has been argued that when individuals associate specific health behaviors with enhancing their self-esteem, they are more likely to engage in those behaviors when mortality is made salient (Routledge, Arndt, \& Goldenberg, 2004). Specifically, Taubman Ben-Ari, Florian, and Mikulincer (1999) found that among those for whom driving is important to their self-esteem, they reported increased intentions to take driving risks and increased driving speeds in a driving simulator after their mortality was made salient. Similarly, Jessop, Albery, Rutter, and Garrod (2008) found that among young males who viewed driving fast as important to their self-esteem, exposure to mortality-salient risk information about driving fast increased intentions to take driving risks and to drive fast. Lastly, Jessop and Wade (2008) found that among those who perceived binge drinking to be important to their self-esteem (both binge drinkers and non-binge drinkers), they reported greater willingness to binge drink after seeing mortality-salient risk information about binge drinking.

On a related point, TMT posits that maintaining faith in cultural worldviews also help to protect individuals from death-related anxiety by contributing to self-esteem building (Greenberg, Solomon, \& Pyszczynski, 1997). Cultural worldviews are defined as "humanly created and transmitted beliefs about the nature of reality shared by groups and individuals" (Greenberg et al., 1997, p. 65). Maintaining faith in cultural worldviews help to boost a person's self-esteem by providing him or her the satisfaction of adhering to and upholding shared societal values (Greenberg et al., 1997). Moreover, cultural worldviews act as an anxiety buffer by creating order and meaning for individuals (Greenberg et al., 1997). Particularly in situations where mortality is made salient, this elicits an increase in the need to defend and strengthen one's cultural worldviews (Greenberg et al., 1997). Past TMT studies consistently find that beliefs in one's cultural worldviews are stronger following mortality-salient manipulations than non-mortality-salient manipulations (e.g., Arndt, Solomon, Kasser, \& Sheldon, 2004; Rosenblatt, Greenberg, Solomon, Pyszczynski, \& Lyon, 1989). Binge drinking has been argued to be a cultural worldview held by many college students. According to TMT, a cultural worldview is a behavior that should be shared and provide self-esteem to help buffer mortality-related anxiety (Rosenblatt et al., 1999). Binge drinking meets both criteria in that: (1) a large proportion of college students engage in drinking, and as such, are likely to hold similar beliefs about alcohol consumption (Wechsler, Molnar, Davenport, \& Baer, 1999) and (2) studies have shown that some college students drink alcohol to enhance their self-worth and sense of belonging (e.g., Glindemann, Geller, \& Fortney, 1999; McCormack, Laybold, Dickerson-Nelson, \& Budd, 1993). Binge drinking is also a behavior that some individuals feel are endorsed by their cultural worldviews (e.g., Johnston \& White, 2003). Thus, binge drinking is an appropriate context in which to test TMT predictions.

The anxiety-buffer hypothesis states that if a psychological structure (e.g., self-esteem or faith in a cultural worldview) provides a buffer against anxiety, it is expected that strengthening the structure will make an individual less prone to exhibit anxiety in response to threats, whereby weakening the structure will make an individual more prone to exhibit anxiety in response to threats (Harmon-Jones, Simon, Greenberg, Pyszczynski, Solomon, \& McGregor, 1997). According to TMT, when mortality is made salient, "if a message's advocated worldview admonishes the worldview held by a message recipient, the message recipient will reject the advocated worldview and defend the preexisting worldview relevant to the context" (Shehryar \& Hunt, 2005, p. 276). In other words, it is expected that for individuals in which binge drinking is part of their cultural worldview, exposure to mortality-salient anti-binge drinking messages will result in message rejection. On the other hand, message rejection is not expected when the anti-binge drinking message is non-mortality-salient because this should not activate self-esteem/cultural worldview defenses. In their study, Shehryar and Hunt (2005) found that when mortality was made salient, message rejection was higher among those who held a high precommitment to binge drinking than those with a low precommitment to binge drinking. However, when mortality was not made salient as a binge drinking risk, there were no significant differences in message rejection between the high and 
low precommitment groups. Hence, in this study an interaction effect is expected between participants' level of binge drinking-based self-esteem and mortality salience of an anti-binge drinking PSA on attitudes and intentions toward binge drinking such that:

H1: When exposed to a mortality-salient anti-binge drinking PSA, participants with high binge drinking-based self-esteem will report more positive binge drinking attitudes and lower intentions to not binge drink than those with low binge drinking-based self-esteem.

In addition to defending or strengthening one's cultural worldview as a response to death-related anxiety, TMT posits that individuals may also rely on the use of proximal defenses (e.g., denial, avoidance) as a means to suppress death-related anxiety immediately following exposure to mortality-salient information. The use of proximal defenses in TMT is similar to Witte's $(1992,1994)$ discussion of fear control processes where an individual enacts defensive avoidance to cope with the fear elicited by a fear appeals message. Thus it is predicted that:

H2: When exposed to a mortality-salient anti-binge drinking PSA, participants with high binge drinking-based self-esteem will report more message avoidance than those with low binge drinking-based self-esteem.

H3: When exposed to a mortality-salient anti-binge drinking PSA, participants with high binge drinking-based self-esteem will more negatively evaluate the claims made in the PSA than those with low binge-drinking based self-esteem.

\section{Fear Appeals}

Messages indicating what negative consequences an individual will face if they fail to comply with the recommendations made within the message are known as fear appeals. Perceived susceptibility and perceived severity contribute to the level of threat individual experiences in response to a fear appeal message (Witte, 2002). An increased perception of threat is positively correlated to an increased desire to avoid the threat as well as experiencing the emotion of fear (Witte, 1992). The desire to avoid threat can be a strong motivation, and so messages inducing threat while suggesting the message receiver alter their actions in order to avoid threat are persuasive. Fear appeals have long been used in persuasive messages to elicit emotional responses in message receivers. Persuasion and fear has been shown to be positively correlated (Leventhal, 1971). Fear can elicit persuasive outcomes either directly or indirectly (Dillard \& Anderson, 2004). Because fear inspires an elevated level of arousal and is "perceived to be significant and personally relevant" (Witte, 1992, p.331), an individual processes fear appeal messages both cognitively, by recognizing and understanding the primary message, and emotionally, through their response to the fear appeal.

Leventhal (1971) developed the Parallel Process Model to explain the cognitive appraisal process that individuals went through in response to fear appeals. According to the Parallel Process Model, only if the threat of repercussion is greater than the perceived positive outcomes of the behavior will individuals change their planned behaviors (Rogers, 1983). Though the Parallel Process Model provided an explanation for how fear appeals are cognitively appraised, some researchers felt the focus was too narrow. As a response, Witte (1992) proposed the Extended Parallel Process Model (EPPM). Witte's $(1992,1994)$ EPPM combines aspects of both Leventhal's (1971) Parallel Process Model and Roger's (1983) Protection Motivation Theory and explains not only when and why fear appeals are effective, but also when and why they sometimes fail. According to the EPPM, when individuals are exposed to a fear appeals message, two message appraisal processes occur at the same time: threat appraisal and efficacy appraisal. The threat appraisal involves assessment of the severity of the threat and susceptibility to the threat. When both perceptions are high, the emotion of fear is elicited motivating further message processing. Once fear is experienced, individuals may enact an adaptive or maladaptive response based on efficacy appraisal. The assessment of efficacy includes both self-efficacy and response efficacy. Self-efficacy refers to the belief that one is able to perform the recommended behavior in order to avert the threat (Witte, 1994).

On the other hand, response efficacy deals with an individual's perception of the effectiveness of the recommended response to avert the threat (Witte, 1994). Based on these two message appraisals, three fear appeal effects are possible: (a) no effect, (b) danger control, and (c) fear control. When perceived threat and efficacy are low, fear appeals are said to produce no effects on behavior change. When perceived threat is high, fear appeals may either facilitate positive or negative behavior change, depending on the assessment of efficacy. If perceived efficacy is high, danger control responses will be the dominant method used by individuals to reduce their feelings of fear via enactment of the recommended action within the fear appeal (Witte, 1994). Conversely, if perceived efficacy is low, the individual will employ fear control responses that primarily involve the use of denial of the threat and defensive avoidance of the fear appeal. Numerous studies have tested for the 
effects of threat and efficacy appeals on behavioral intentions and behavior change (for review, see Witte \& Allen, 2000). Overall, high threat, high efficacy messages generally produce the most positive impact on behaviors, whereas low threat, low efficacy messages produce the least positive impact on behaviors (Witte \& Allen, 2000). Moreover, it has been argued that there is an interaction effect between threat and efficacy on behaviors, such that the effect of threat on behaviors is positive only when efficacy is high (Witte, 1992, 1994). Thus, in this study an interaction effect is expected between participants' level of perceived threat about binge drinking and their perceived efficacy to not binge drink on attitudes and intentions toward binge drinking such that:

H4: When perceived threat about binge drinking and perceived efficacy related to not binge drinking are both high, participants will report more negative binge drinking attitudes and higher intentions to not binge drink than any other combination of perceived threat and perceived self-efficacy.

Dillard (1994) has argued that response to fear is only half of a fear appeal, the message should also provide a fear relief element. Most fear appeals models, including the EPPM focus only on understanding the adaptive responses to the fear appeal, but neglects to consider the maladaptive responses. EPPM is limited in that the model only addresses assessment of the adaptive response to a health threat (i.e., response and self-efficacy) but discounts the potential impact of the maladaptive response to a health threat (i.e., response costs and maladaptive rewards). As described within Protection Motivation Theory (PMT; Rogers, 1983), in response to a threatening situation, individuals may choose to enact a maladaptive response (i.e., reject the recommended behavior for averting the threat) based on their assessment of the response costs (i.e., perceived costs associated with enacting the recommended behavior change) and maladaptive rewards (i.e., perceived rewards of continuing the unhealthy behavior). These perceptions are typically measured using Likert-scales where respondents are presented with a set of negative consequences associated with enacting the recommended behavior change (response cost) and positive consequences associated with continuing the unhealthy behavior (maladaptive rewards) and asked their level of agreement (Rogers, 1983). As an initial step to extend the EPPM, the current study proposes to include response costs as part of the message appraisal process.

RQ1: To what extent does response cost to not binge drink predict attitudes and intentions toward binge drinking above and beyond the EPPM variables related to binge drinking?

\section{Methods}

\subsection{Participants}

Undergraduate students $(\mathbf{N}=264)$ were recruited from a large Midwestern university from various communication classes via a recruitment flier sent out to instructors using e-mail. The flier asked for participants to take part in a study designed to evaluate their cognitive and emotional reactions to a PSA message that may or may not be related to alcohol consumption. The flier contained a web link where interested individuals could go to take part in the study. Participants ranged in age from 18-24 $(\mathbf{M}=19.92, \mathbf{S D}=1.96)$ and were offered research credit for their participation in the study. The current sample was comprised of 80 males and 184 females. Approximately $26.2 \%$ of the participants were freshmen, $35.6 \%$ sophomores, $19.7 \%$ juniors, and $18.6 \%$ seniors. When asked to indicate their ethnicity, $75.4 \%$ of respondents identified themselves as White, $6.4 \%$ Black, $6.1 \%$ Hispanic, 6.8\% Asian, and 5.3\% American Indian.

\subsection{Study Design}

A quasi-experimental design was used in this study. Participants were randomly assigned to 1 of 5 message viewing conditions. Two of the message viewing conditions featured a mortality-salient anti-binge drinking PSA. Two other message-viewing conditions featured a non-mortality-salient anti-binge drinking PSA. One message viewing condition served as the control ad in which a car commercial was used that did not mention any information related to alcohol or alcohol consumption. The decision to include an unrelated appeal was to avoid the potential confound of providing basic information related to the risks of binge drinking to participants given that such risk information alone may be sufficient to make mortality salient (e.g., Jessop \& Wade, 2008). We also decided to include 2 anti-binge drinking PSAs per mortality-salience condition to increase the external validity of the outcomes achieved.

To test the proposed set of hypotheses, a 2 × 2 factorial design was used crossing mortality-salience of the anti-binge drinking PSA (mortality-salient, non-mortality-salient), and level of participants' binge drinking-based self-esteem (low, high) with an offset control group that watched an ad not mentioning anything related to alcohol consumption. A median split was performed on the binge drinking-based self-esteem measure to create the low (i.e., those who scored one median absolute deviation below the median) and high (i.e., those who scored one mean absolute deviation above the median) groups of binge drinking-based self-esteem. Those that scored 
within +/- one median absolute deviation of the median were not included in the analyses. This was done to ensure that we had high and low binge-drinking self-esteem groups accurately represented in the final sample.

\subsection{Stimulus Advertisements}

For this study, two types of anti-binge drinking (mortality-salient, non-mortality salient) PSAs were selected from a variety of PSAs found online via YouTube that aimed to curb binge drinking among college students. Mortality-salient anti-binge drinking PSAs were those ads that explicitly featured images of death as part of the overall appeal (e.g., seeing a person blacking out from binge drinking and then flat lining). In one of the mortality-salient PSAs, a young couple is shown having a fight leading her significant other to leave the apartment while the young woman started binge drinking with her friends. She is shown drinking shot after shot until she passes out on the sofa. Her boyfriend returns to find her unresponsive as the sound of a beating heart is heard getting louder and louder before flat lining to indicate that she had died. A tag line asks the question, "Is this the right choice?" The other mortality-salient PSA showed a group of friends partying at a nightclub with one of them drinking heavily. As they leave, he stumbles out and collapses outside the club, and is unresponsive as his friends try to wake him up. The sound of a beating heart is heard and gets louder and louder before flat lining. A tag line asks the question "Is this the right choice?"

Non-mortality-salient anti-binge drinking PSAs were those ads that did not explicitly show images of death as a result of binge drinking, but did show some other negative consequences from binge drinking (e.g., seeing images of a person getting assaulted, injuring themselves after passing out from binge drinking, and vomiting from excessive drinking). One of the non-mortality-salient PSAs shows the life a young woman in a series of flashbacks documenting her binge drinking behavior. The clips show various scenes of her binge drinking at different parties ending with the sound of crashing glass. It is assumed that she was involved in a car accident but we do not know the nature of her injuries. The other non-mortality-salient PSA features a young woman binge drinking at a club and as she continues, we see quick scenes where she is physically assaulted by several young men, as well as her falling down several times). She wakes up the next morning and is shown stumbling out of an apartment after throwing up in a bathroom. The voiceover comes on to talk about the negative outcomes of binge drinking that are not death-related. All of the binge drinking PSAs featured college-aged students binge drinking within a social context (e.g., at a party/club). The control ad was a Volkswagen car commercial that featured a little boy in a Darth Vader costume using "the force" to start the car. Production value of the videos was for the most part consistent in that the mortality-salient and non-mortality salient anti-binge drinking PSAs had similar picture quality. All the videos were also consistent in terms of their lengths. All five videos used for this study were between fifty seconds and one minute forty seconds long with the mean length being one minute sixteen seconds. We did not measure the amount of time participants spent viewing the video but the time for completing the study was comparable across the five conditions.

\subsection{Procedures}

Participants were first directed to a link to the Qualtrics survey website where they read a consent form and indicated acceptance by clicking a button to either accept or not accept the statement of consent provided. For this study, five different message conditions were employed: (1) mortality-salient anti-binge drinking PSA\#1 $(\mathbf{n}=44)$, (2) mortality-salient anti-binge drinking PSA \#2 ( $\mathbf{n}=45)$, (3) non-mortality-salient anti-binge drinking PSA \#1 (n=44), (4) non-mortality-salient anti-binge drinking PSA \#2 ( $\mathbf{n}=43$ ), and (5) control advertisement (i.e., car commercial) $(\mathbf{n}=88)$. After exploratory analyses found no significant differences within the 2 mortality-salient the 2 non-mortality-salient conditions on the key study variables, a decision was made to combine the conditions to form a single mortality-salient condition $(\mathbf{n}=89)$ and a single non-mortality-salient condition $(\mathbf{n}=87)$ that also allowed us to have approximate equal cell sizes. Participants were randomly assigned to the different ad conditions.

Prior to watching the ads, all participants completed questions assessing their level of binge drinking-related self-esteem and binge drinking behaviors, Participants were then directed to an online link opening up a new window where they were asked to watch a short PSA/commercial. that may serve a proximal defense function. As is typical in TMT studies, following exposure to the mortality-salient induction (i.e., PSA), participants were asked to respond to a series of items to serve as a distraction to allow time for proximal defenses to pass, and death-thought accessibility to heighten (Pyszczynski, Greenberg, \& Solomon, 1999). Specifically, participants were asked to description of some of the ad's elements such as how many males and females were shown in the ad, what was the setting of the ad (e.g., at an apartment, at a club), the name of the organization sponsoring the $\mathrm{ad}$, and the tag line from the ad. This distractor task also served as a check to ensure that participants had at least viewed the ad completely. Respondents who failed to provide the correct information had their data dropped 
from the study. To ensure that participants spent adequate time on the distractor task, the survey was set up in such a way that participants were not allowed to continue to the next part of the survey until a specific amount of time had elapsed (i.e., 6 minutes). This restriction was added to allow sufficient time for proximal defense to pass. Participants then completed measures aimed at assessing the enactment of fear control processes (e.g., message avoidance, negative ad evaluations). Given that these items were assessed after the distractor task, it could be argued that they served as measures of distal defense as opposed to proximal defense.

Participants were then asked to provide their cognitive reaction to the ad, specifically the extent to which the ads made them consider their own mortality (i.e., level of death-thought accessibility). These items were asked after the distractor task to allow for proximal defense to pass. Following this, respondents completed measures assessing their attitudes toward binge drinking and intentions to not binge drink. Both of these were the main outcome variables of interest to assess the enactment of distal defenses. Lastly, participants were asked about their perceived severity and susceptibility to binge drinking harms, perceived response and self-efficacy related to not binge drinking, and perceived response costs to not binge drink. They were then instructed to provide the necessary information for them to receive research credit and thanked for their participation.

\subsection{Measures}

\subsubsection{Binge Drinking-Based Self-Esteem}

Two sets of items were used to assess the implications binge drinking had for participants' self-esteem. The first set of eight items directly measured participants' perceptions of binge drinking for their self-esteem (e.g., binge drinking helps me feel like a person of worth, binge drinking makes me feel good about myself, being able to binge drink is an important part of who I am as a person). The second set of two items assessed the extent to which binge drinking is endorsed by the participants' cultural worldview (e.g., my friends would disapprove of me if I binge drink, it is acceptable for people in our society today to binge drink). All of the items were measured on a 5-point scale from (1) strongly disagree to (5) strongly agree and taken from previous binge drinking studies (e.g., Jessop et al., 2008; Jessop \& Wade, 2008). All of the items were averaged into an index and yielded a good reliability $(\alpha=.86)$. As mentioned, a median split was performed on the scale to create two groups, those with high binge drinking-based self-esteem and those with low binge drinking-based self-esteem.

\subsubsection{Message Avoidance}

Participants were asked to respond to four items that assessed the extent to which the PSA/commercial made them want to avoid thinking about: (a) the negative effects of binge drinking, (b) the dangers of binge drinking, (c) the harms of binge drinking, and (d) how binge drinking negatively affects my health. The measures were specifically created for this study, item averaged into an index yielding high reliability $(\alpha=.90)$.

\subsubsection{Negative Ad Evaluation}

Participants were asked a series of items assessing the extent to which they felt the PSA/commercial exaggerated the dangers associated with binge drinking (e.g., exaggerated the negative consequences of binge drinking, overstated the dangers of binge drinking, tried to mislead me about the dangers of binge drinking). These items were adopted from the ones used in previous PSA evaluation studies (e.g., Wong \& Cappella, 2009). The six items used a 5-point scale from (1) strongly disagree to (5) strongly agree and averaged into an index that yielded a strong reliability $(\alpha=.94)$.

\subsubsection{Death Thought Accessibility}

Participants' level of thoughts about mortality after exposure to the PSA/commercial was measured using seven modified items taken from the revised Death Anxiety Scale (Thorson \& Powell, 1992). Specifically, respondents reported the extent to which they agreed that ad they viewed made them think about: (a) the shortness of life, (b) missing out on so much after you die, (c) how it will feel to be dead, (d) the total isolation of death, (e) dying young, (f) the pain involved in dying, and (g) my lack of control over the process of dying. The items were assessed using a 5-point scale from (1) strongly disagree to (5) strongly agree. An index was created by averaging across the items yielding a high reliability $(\alpha=.90)$.

\subsubsection{Attitudes toward Binge Drinking}

Four items were used to measure participants' attitudes toward binge drinking. Specifically, respondents were asked to extent to which they felt binge drinking was (a) bad-good, (b) worthless-worthwhile, (c) negative-positive, (d) foolish-wise. The semantic differential measure was adopted from previous attitudinal studies (e.g., Wong \& Cappella, 2009; Smith-McLallen, Hornik, \& Fishbein, 2011). The items were assessed using a 5-point scale and averaged into an index yielding a high reliability $(\alpha=.94)$. 


\subsubsection{Intentions to Not Binge Drink}

Participants' intentions to not binge drink in the next 3 months were assessed using four items. Specifically, respondents were asked the extent to which they intended to: (a) monitor more closely their drinking behaviors at social/sporting events, (b) reduce their overall alcohol consumption at social/sporting events, (c) avoid engaging in binge drinking at social/sporting events, and (d) limit my drinking behaviors at social/sporting events. These items were specifically created for this study and averaged into an index that yielded a high reliability $(\alpha=.93)$. The items were measured using 5-point scales from (1) strongly disagree to (5) strongly agree.

\subsubsection{Perceived Severity and Susceptibility to Binge Drinking Harms}

Four items each were used to measure participants' level of perceived severity regarding binge drinking (i.e., poses a serious health threat, can severely harm their body, significant health concern, and has deadly consequences) and their perceived susceptibility to experiencing these harms (i.e., vulnerable to the dangers of binge drinking, likely to experience negative effects, susceptible to the danger, and likely to experience the danger). All items were measured on a five-point scale from (1) strongly disagree to strongly agree. An index was created for perceived severity $(\alpha=.96)$ and one for perceived susceptibility $(\alpha=.95)$. The items were adopted from previous fear appeals studies (e.g., Witte, 1992, 1994; Wong \& Cappella, 2009).

\subsubsection{Perceived Response and Self-efficacy Related to Not Binge Drink}

Four items were used to assess participants' perceived response efficacy regarding not binge drinking. Specifically, respondents were asked the extent they agreed that drinking responsibly (i.e., to not binge drink) would help them: (a) avoid the harms related with binge drinking, (b) prevent experiencing binge drinking harms, (c) significantly reduces your chances of dying from alcohol poisoning, and (d) lessen the severity of the effects experienced due to drinking. These items were modified from those used in Witte $(1992,1994)$ and averaged into an index yielding a strong reliability $(\alpha=.98)$. Four items measured participants' perceived self-efficacy to not binge drink (e.g., control your overall alcohol consumption, avoid drinking to the point of passing out, drink responsibly and not binge drink). Similar to response efficacy, the modified self-efficacy measures were adopted from Witte $(1992,1994)$ and averaged into an index yielding a high reliability $(\alpha=.95)$. All of the items were assessed on a 5-point scale from (1) strongly disagree to (5) strongly agree.

\subsubsection{Perceived Response Costs Associated with Not Binge Drinking}

Five items were created in this study to evaluate the extent to which participants felt that by not binge drinking, they would experience several response costs such as: (a) fit in less with your friends, (b) feel more socially isolated from others, (c) feel less like you are part of your group, (d) look less cool in the eyes of others, and (e) feel more anxious interacting with others. The items were measured on a 5-point scale from (1) strongly disagree to (5) strongly agree, and averaged into an index that yielded a high reliability $(\alpha=.93)$.

\section{Results}

\subsection{Binge Drinking Status and Frequency}

Past-year binge drinkers were defined as those males who reported at least 1 occasion in the past 12 months they have had 5 or more drinks in a row in a 2 -hour period, and females who reported at least 1 occasion in the past 12 months having had 4 or more drinks in a row in a 2 -hour period. For the current sample, $69.9 \%$ of the females were past-year binge drinkers and $67.9 \%$ of the males were past-year binge drinkers. Overall, $69.7 \%$ of the sample can be classified as past-year drinkers. This figure is comparable to the study conducted by Cranford et al. (2006) in their test of the new binge drinking measure (i.e., 63.6\% of college students were classified as past-year binge drinkers).

As for frequency of binge drinking, within this sample, among males, $7.6 \%$ reported engaging in binge drinking less than 1-2 times in the past year, 15.4\% reported binge drinking between 3-5 times in the past year, 10.3\% reported binge drinking between 6-9 times in the past year, and 34.6\% reported engaging in binge drinking more than 10 times in the past year. Among females, 16.9\% reported engaging in binge drinking 1-2 times in the past year, 20.2\% reported binge drinking between 3-5 times in the past year, $13.1 \%$ reported binge drinking between 6-9 times in the past year, and 19.7\% reported engaging in binge drinking more than 10 times in the past year. The data clearly shows that while more females were classified as past-year binge drinkers, males engaged in binge drinking on more occasions than females in the past 12 months.

\subsection{Manipulation Checks}

An Analysis of Variance (ANOVA) was performed on the data set to determine whether the mortality-salience manipulation was successful. Mortality-salience condition (mortality-salient PSA, non-mortality-salient PSA, 
and control ad) served as the independent factor with the death thought accessibility measure as the dependent variable. The results indicated a significant main effect of mortality-salience condition on death thought accessibility, $\mathbf{F}(2,261)=67.24, \mathbf{p}<.001, \boldsymbol{\eta} \mathbf{2}=.34$. Participants who viewed the mortality-salient PSAs reported experiencing significantly higher levels of thoughts about death after watching the ad $(\mathbf{M}=3.35, \mathbf{S D}=.95)$ than those exposed to either the non-mortality-salient PSAs $(\mathbf{M}=2.84, \mathbf{S D}=.85)$ or the control ad $(\mathbf{M}=1.84, \mathbf{S D}=.83)$. Thus, the results show that we were able to successfully manipulate mortality-salience via the use of a mass-mediated message (i.e., PSA).

\subsection{Test of Hypotheses}

In order to test the hypotheses one through four, a series of ANOVAs were performed on the data set crossing participants' binge drinking-based self-esteem (high, low) with mortality-salience ad condition (mortality-salient, non-mortality-salient, control) on various dependent variables examined in the individual hypotheses. An interaction term was created to specifically test for interaction effects.

\subsubsection{Hypothesis One}

The first hypothesis predicted an interaction effect between participants' binge drinking-based self-esteem and mortality-salience ad condition on binge drinking attitudes and intentions to not binge drink. Significant interaction effects were found on binge drinking attitudes, $\mathbf{F}(2,258)=13.18, \mathbf{p}<.001, \boldsymbol{\eta} \mathbf{2}=.08$, and on intentions to not binge drink,

$\mathbf{F}(2,258)=10.53, \mathbf{p}<.001, \boldsymbol{\eta} 2=.06$. Specifically $\mathrm{H} 1$ predicted that when exposed to mortality-salient PSAs, participants with high binge drinking-based self-esteem would report more positive binge drinking attitudes and lower intentions to not binge drink than those with low binge drinking-based self-esteem. Examining the estimated means, when exposed to death-salient anti-binge drinking PSAs, those with high binge drinking-based self-esteem reported more positive binge drinking attitudes $(\mathbf{M}=2.74, \mathbf{S E}=.16)$ than those with low binge drinking-based self-esteem $(\mathbf{M}=1.34, \mathbf{S E}=.15), t(87)=-5.39, p<.001$. Conversely, when exposed to death-salient anti-binge drinking PSAs, those with high binge drinking-based self-esteem reported lower intentions to not binge drink (M=2.37, $\mathbf{S E}=.18)$ than those with low binge drinking-based self-esteem $(\mathbf{M}=3.94, \mathbf{S E}=.16)$, $t(87)=6.55, p<.001$. Taken together, $\mathrm{H} 1$ was supported. Tables 1 and 2 summarize the estimated marginal means and standard errors for the different groups on binge drinking attitudes and intent to not binge drink.

Table 1. Summary of Estimated Marginal Means and Standard Errors for Binge Drinking Attitudes by Mortality-Salience Condition and Binge Drinking-Based Self-Esteem

\begin{tabular}{|c|c|c|c|}
\hline Condition & Mean & SE & $\mathrm{n}$ \\
\hline Mortality-Salient Anti-Binge Drinking PSAs & $2.05^{\mathrm{a}}$ & .11 & 89 \\
\hline High binge drinking-based self-esteem & $2.74^{1}$ & .15 & 41 \\
\hline Low binge drinking-based self-esteem & $1.37^{2}$ & .16 & 48 \\
\hline Non-Mortality-Salient Anti-Binge-Drinking PSAs & $1.52^{\mathrm{b}}$ & .11 & 87 \\
\hline High binge drinking-based self-esteem & 1.55 & .15 & 47 \\
\hline Low binge drinking-based self-esteem & 1.49 & .17 & 40 \\
\hline Control Commercial (Volkswagen Ad) & $2.39^{\mathrm{a}}$ & .11 & 88 \\
\hline High binge drinking-based self-esteem & 2.37 & .14 & 48 \\
\hline Low binge drinking-based self-esteem & 2.40 & .17 & 40 \\
\hline
\end{tabular}

Note: Different superscript letters indicate significant differences between ad conditions $(p<.01)$ while different superscript numbers indicate significant differences within ad conditions $(p<.001)$. 
Table 2. Summary of Estimated Marginal Means and Standard Errors for Intentions to Not Binge Drink by Mortality-Salience Condition and Binge Drinking-Based Self-Esteem

\begin{tabular}{rlll}
\hline Condition & Mean & SE & $\mathrm{n}$ \\
\hline Mortality-Salient Anti-Binge Drinking PSAs & $3.16^{\mathrm{a}}$ & .12 & 89 \\
High binge drinking-based self-esteem & $2.37^{1}$ & .18 & 41 \\
Low binge drinking-based self-esteem & $3.95^{2}$ & .16 & 48 \\
& & & 87 \\
Non-Mortality-Salient Anti-Binge-Drinking PSAs & $3.45^{\mathrm{a}}$ & .12 & 47 \\
High binge drinking-based self-esteem & 3.38 & .16 & 40 \\
Low binge drinking-based self-esteem & 3.51 & .18 & 88 \\
Control Commercial (Volkswagen Ad) & & .12 & 48 \\
High binge drinking-based self-esteem & $2.51^{\mathrm{b}}$ & .15 & .19 \\
Low binge drinking-based self-esteem & 2.70 & 40 \\
\hline
\end{tabular}

Note: Different superscript letters indicate significant differences between ad conditions $(p<.01)$ while different superscript numbers indicate significant differences within ad conditions $(p<.001)$.

\subsubsection{Hypotheses Two and Three}

The second and third hypotheses predicted an interaction effect between participants' binge drinking-based self-esteem and mortality-salience ad condition on message avoidance and negative evaluation of the ad. Significant interaction effects were found on message avoidance of the PSA, $\mathbf{F}(2,258)=5.02, \mathbf{p}<.01, \boldsymbol{\eta} \mathbf{2}=.03$, and on negative ad evaluation, $\mathbf{F}(2,258)=3.41, \mathbf{p}<.05, \boldsymbol{\eta} \mathbf{2}=.02$. Specifically, $\mathrm{H} 2$ predicted that when exposed to mortality-salient PSAs, participants with high binge drinking-based self-esteem would report more message avoidance than those with low binge drinking-based self-esteem. The estimated marginal means show that when exposed to the death-salient anti-binge drinking PSAs, high binge drinking-based self-esteem individuals $(\mathbf{M}=3.60, \mathbf{S E}=.16)$ reported greater message avoidance than those with low binge drinking-based self-esteem $(\mathbf{M}=2.58, \mathbf{S E}=.15), t(87)=-4.39, p<.001$.

The third hypothesis predicted that after viewing the mortality-salient PSAs, those with high binge drinking-based self-esteem would more negatively evaluate the PSA than individuals with low binge drinking-based self-esteem. Looking at the estimated marginal means, we see that after viewing the mortality-salient anti-binge drinking PSAs, high binge drinking-based self-esteem individuals $(\mathbf{M}=3.28, \mathbf{S E}=.15)$ reported more negative evaluation of the claims made in the PSA than those with low binge drinking-based self-esteem $(\mathbf{M}=2.48, \mathbf{S E}=.14), t(87)=-3.55, p<.01$.Thus, $\mathrm{H} 2$ and $\mathrm{H} 3$ were both supported. Tables 3 and 4 summarize the estimated marginal means and standard errors for the different groups on message avoidance and negative evaluation of the ads.

Table 3. Summary of Estimated Means and Standard Errors for Message Avoidance by Mortality-Salience Condition and Binge Drinking-Based Self-Esteem

\begin{tabular}{rlll}
\hline Condition & Mean & SE & \\
\hline Mortality-Salient Anti-Binge Drinking PSAs & $3.09^{\mathrm{a}}$ & .11 & $\mathrm{n}$ \\
High binge drinking-based self-esteem & $3.61^{1}$ & .16 & 41 \\
Low binge drinking-based self-esteem & $2.58^{2}$ & .15 & 48 \\
& & & \\
Non-Mortality-Salient Anti-Binge-Drinking PSAs & $2.74^{\mathrm{a}}$ & .11 & 47 \\
High binge drinking-based self-esteem & 2.95 & .15 & 40 \\
Low binge drinking-based self-esteem & 2.54 & .17 & \\
Control Commercial (Volkswagen Ad) & & & \\
High binge drinking-based self-esteem & 1.62 & .11 & .14 \\
Low binge drinking-based self-esteem & 1.59 & .18 & 48 \\
\hline
\end{tabular}

Note: Different superscript letters indicate significant differences between ad conditions $(p<.01)$ while different superscript numbers indicate significant differences within ad conditions $(p<.001)$. 
Table 4. Summary of Estimated Means and Standard Errors for Negative Ad Evaluation by Mortality-Salience Condition and Binge-Drinking Related Self-Esteem

\begin{tabular}{llll}
\hline Condition & Mean & SE & $\mathrm{n}$ \\
\hline Mortality-Salient Anti-Binge Drinking PSAs & $2.88^{\mathrm{a}}$ & .10 & 89 \\
High binge drinking-related self-esteem & $3.28^{1}$ & .15 & 41 \\
Low binge drinking-related self-esteem & $2.48^{2}$ & .14 & 48 \\
Non-Mortality-Salient Anti-Binge-Drinking PSAs & $2.44^{\mathrm{b}}$ & .10 & 87 \\
High binge drinking-related self-esteem & 2.50 & .14 & 47 \\
Low binge drinking-related self-esteem & 2.39 & .15 & 40 \\
Control Commercial (Volkswagen Ad) & $1.57^{\mathrm{c}}$ & .10 & 88 \\
High binge drinking-based self-esteem & 1.66 & .13 & 48 \\
Low binge drinking-based self-esteem & 1.48 & .16 & 40 \\
\hline
\end{tabular}

Note: Different superscript letters indicate significant differences between ad conditions $(p<.01)$ while different superscript numbers indicate significant differences within ad conditions $(p<.001)$.

\subsubsection{Hypothesis Four}

The fourth hypothesis was derived from EPPM predictions, such that an interaction effect was expected between perceived threat about binge drinking and perceived efficacy related to not binge drinking on binge drinking attitudes and intentions to not binge drink. To test this hypothesis, two linear regression models were examined with perceived binge drinking threat (i.e., perceived severity and perceived susceptibility) and perceived efficacy related to not binge drinking (i.e., response efficacy and self-efficacy) as independent predictors. An interaction term was created and entered in step 2 of the regression models. Table 5 summarizes the means and standard deviations for the key EPPM variables.

Table 5. Summary of Means and Standard Deviations for Key EPPM Variables

\begin{tabular}{lll}
\hline Variables & Mean & SD \\
\hline Binge drinking severity & 4.08 & .89 \\
Susceptibility to binge drinking harms & 2.50 & 1.14 \\
Response efficacy related to not binge drinking & 3.83 & .97 \\
Self-efficacy to not binge drink & 4.17 & .93 \\
Response costs associated with not binge drinking & 2.54 & 1.20 \\
Intentions to not binge drink & 3.04 & 1.28 \\
\hline
\end{tabular}

Note: For binge drinking attitudes, while the overall model was significant, $\mathbf{R}=.20$, adjusted $\mathbf{R}^{2}=.04, \mathbf{F}(3$, $260)=3.64, \mathbf{p}<.01, \boldsymbol{\eta} \mathbf{2}=.04$, the interaction effect was not significant, $\boldsymbol{\beta}=.60, \mathbf{p}=.13$. Only perceived efficacy to not binge drink was a significant negative predictor of binge drinking attitudes, $\boldsymbol{\beta}=-.15, \mathrm{p}<.05$. As for intentions to not binge drink, while the overall model was significant, $\mathbf{R}=.31$, adjusted $\mathbf{R}^{2}=.09, \mathbf{F}(3,260)=9.35, \mathbf{p}<.001, \boldsymbol{\eta} \mathbf{2}$ $=.10$, the interaction effect was not significant, $\boldsymbol{\beta}=.01, \mathbf{p}=\mathrm{ns}$. Both perceived binge drinking threat $(\boldsymbol{\beta}=.16, \mathbf{p}<.01)$ and perceived efficacy related to not binge drinking $(\boldsymbol{\beta}=.23, \mathbf{p}<.001)$ were significant positive predictors of intentions to not binge drink in the next 3 months. Taken together, $\mathrm{H} 4$ was not supported.

\subsection{Research Question}

A research question was posed to examine the extent to which response costs influenced participants' intentions to not binge drink in the next 3 months. The EPPM primarily makes predictions about how adaptive response appraisals influence people's reactions to fear appeals, but neglects to consider the impact of maladaptive response appraisals. A hierarchical linear regression model was tested with perceived binge drinking threat (step 1), perceived efficacy related to not binge drinking (step 1), and perceived response cost associated with not binge drinking (step 2) as independent predictors of intentions to not binge drink. The overall model was significant, $\mathbf{R}=.50$, adjusted $\mathbf{R}^{2}=.24, \mathrm{~F}(3,260)=28.54, \mathbf{p}<.001, \boldsymbol{\eta} \mathbf{2}=.25$. After accounting for both perceived binge drinking threat $(\boldsymbol{\beta}=.20, \mathbf{p}<.001)$ and perceived efficacy related to not binge drinking $(\boldsymbol{\beta}=.21, \mathbf{p}<.01)$, perceived response costs associated with not binge drinking $(\boldsymbol{\beta}=-.39, \mathbf{p}<.001)$ was a significant negative predictor of intentions to not binge drink in the next 3 months.

\section{Discussion}

The main purpose of this study was to examine how individuals with low or high levels of binge drinking-based self-esteem would respond to anti-binge drinking PSAs that either made death as a possible consequence of binge 
drinking salient (i.e., mortality-salient) or not salient (i.e., non-mortality-salient). From a TMT perspective, it was expected that those who based their self-esteem in part to their binge drinking behaviors would react more negatively toward the PSAs that made their mortality salient. In EPPM terms, this meant that these individuals would be most susceptible to enact fear control processes (i.e., defensive avoidance, denial of the risk) as opposed to danger control processes (i.e., to increase intentions to reduce binge drinking behaviors). The rationale was that in the face of mortality-salient information, individuals would cling stronger to their cultural worldviews, particularly when the message directly attacks their cultural worldviews (i.e., that they should not be binge drinking). The results of this study largely supports this argument, as those who held high binge drinking-based self-esteem reported more positive binge drinking attitudes and negative evaluation of the PSA claims, and lower intentions to binge drink in the future compared to those who held low binge drinking-based self-esteem.

Additionally, those who viewed the control ad reported significantly higher binge drinking attitudes $(\mathbf{M}=2.39$, $\mathbf{S E}=.11)$ and lower intentions to not binge drink $(\mathbf{M}=2.51, \mathbf{S E}=.12)$ than those participants who viewed the non-death-salient anti-binge drinking PSAs. Moreover, those who saw the control ad reported significantly lower ad avoidance $(\mathbf{M}=1.61, \mathbf{S E}=.11)$, and lower negative ad evaluation $(\mathbf{M}=1.57, \mathbf{S E}=.10)$ than those participants who watched the death-salient anti-binge drinking PSAs. In hindsight, these results were unsurprising because we did not anticipate the control ad to have much impact on binge drinking attitudes or intentions, nor did we feel the ad would elicit defensive avoidant responses.

A secondary objective of this study was to further examine the EPPM variables to assess whether or not we could add to the existing model. Specifically, we were curious as to the impact of a maladaptive response appraisal (i.e., response cost) on reactions to fear appeals. The results provide good empirical support for the inclusion of response cost assessment as part of the message appraisal process given that it was as strong of a predictor of intentions to not binge drink as perceived binge drinking threat, and stronger than perceived efficacy.

There were a number of limitations to the study design. First, one of the non-mortality-salient PSAs talked about female victimization as a result of binge drinking (e.g., getting assaulted). Given the predominantly female sample, this PSA may have produced a more pronounced effect on female viewers compared to the male viewers. However, no significant interaction effects were found between participant sex and message condition on the different outcome variables examined in this study. Also, there were no significant differences found in terms of exposure to the different PSAs based on sex. And second, the PSAs used were not pilot-tested and so equivalence was assumed across the ads. The PSAs did have equal lengths and had similar picture quality. However, because no pilot testing was done, it is difficult to say for certain if participants perceived similar production quality across the set of PSAs. Future studies should pilot test the PSAs to ensure that production quality of the ads are perceived similarly and that there are not other confounds in the content of the messages (e.g., similar tag lines, similar characters featured, similar dialogue and/or narrative).

\subsection{Implications and Directions for Future Research}

One of the main implications of this study is that health campaigns aimed at reducing binge drinking among college students need to be cautious in terms of the types of PSAs used to target specific segments of binge drinkers. In particular, it may be most useful for anti-binge drinking PSA designers to focus more on non-death-salient negative consequences of binge drinking to reach a broader audience as opposed to using ads that explicitly warn about death from binge drinking (e.g., focusing on alcohol poisoning as an outcome). A limitation of the current study and one that could be explored in future research is whether the inclusion of strong response efficacy information (e.g., \% reduction in your chances of dying by drinking responsibly) as part of the PSA could help alleviate some of the death-related anxiety felt among those who view binge drinking as important for their self-esteem. The results did show that among those with low binge drinking-based self-esteem, mortality-salient PSAs were the most effective and so we may still want to incorporate them in our campaigns.

Another implication of the findings is that anti-binge drinking campaigns may also want to focus efforts at overcoming perceived response costs that binge drinkers have about cessation of their drinking behaviors. In this study, response costs associated with not binge drinking was a strong predictor of people's intentions to not binge drink in the next 3 months. While most alcohol education/awareness programs highlight the negative health and social consequences associated with binge drinking, they need to also acknowledge that there are costs to not participating in binge drinking with peers. One strategy may be to discuss how rather than trying to fit by binge drinking, individuals should strive to be a peer role model, to show that it is not necessary to binge drink to fit in social situations. Also, because response cost is a barrier impeding some people to not binge drink, it may mean campaigns need to target their efforts at influential opinion leaders within peer social networks to alter perceptions of social response costs associated with not binge drinking. 
One avenue for future research not explored in this study was the role of the presence of others on binge drinking decisions. Specifically, Fransen et al. (2011) found that when mortality is made salient, the presence of others amplifies defensive avoidance responses to mortality-salient messages. Therefore, for individuals with high alcohol attachment (i.e., those with high levels of binge drinking-based self-esteem), they are likely to deny or disregard mortality salient messages to an even greater extent when they are around their peers. This would be consistent with the TMT argument that when a person's cultural worldview is challenged by a message that directly attacks that worldview, they will be motivated to defend it, even more so if the challenge is made publicly among their friends. This is a situation that can be tested in future studies.

Just as we would expect those whose self-esteem is derived from their binge drinking behaviors, an equally compelling argument could be made regarding those whose self-esteem is based on the fact they are non-drinkers. Another avenue for research may be to look at how self-esteem derived from holding a non-drinker identity affects these individuals' responses to anti-binge drinking ads. We expect that for this subgroup of individuals, the use of mortality-salient anti-binge drinking PSAs would be highly effective. From a TMT perspective, mortality salience would motivate these individuals to cling stronger to their cultural worldview (i.e., identity as a non-drinker) and so we anticipate their intentions to not binge drink to become stronger. TMT literature would also suggest that non-drinkers have an even stronger reaction to mortality-salient anti-binge drinking PSAs if they are in the presence of their peers when viewing the messages (Fransen et al., 2011).

In closing, this study provided an extension of previous research by Jessop and Wade (2008) in looking at whether or not mortality salience can be manipulated via a mass-mediated message (i.e., a PSA). The results show that we can successfully rely on the use of mass-mediated messages to induce death-related anxiety within our audiences, which could in some situations help to increase the impact of our messages. However, the results of this study also reminds us of the importance of considering unintended effects of campaign messages, as a message that elicits death-related anxiety may lead to positive behavior changes among some people, it may also lead to reinforcement of negative behaviors among others in the population.

\section{References}

Arndt, J., Solomon, S., Kasser, T., \& Sheldon, K. M. (2004). The urge to splurge: A terror management account of materialism and consumer behavior. Journal of Consumer Psychology, 14, 198-212. http://dx.doi.org/10.1207/s15327663jcp1403_2

Becker, E. (1973). The Denial of Death (1st ed.). New York, NY: The Free Press.

Bozo, O., Tunca, A., \& Simsek, Y. (2009). The effect of death anxiety and age on health promoting behaviors: A terror-management theory perspective. The Journal of Psychology, 143(4), 377-389. http://dx.doi.org/10.3200/JRLP.143.4.377-389

Cranford, J. A., McCabe, S. E., \& Boyd, C. J. (2006). A new measure of binge drinking: Prevalence and correlates in a probability sample of undergraduates. Alcoholism: Clinical and Experimental Research, 30(11), 1896-1905. http://dx.doi.org/10.1111/j.1530-0277.2006.00234.x

Dillard, J. P. (1994). Rethinking the study of fear appeals: An emotional perspective. Communication Theory, 4, 295-323.

Dillard, J. P. \& Anderson, J. W. (2004). The role of fear in persuasion. Psychology and Marketing, 21(11), 909-926. http://dx.doi.org/10.1002/mar.20041

Dillard, J. P., \& Peck, E. (2001). Persuasion and the structure of affect: Dual systems and discrete emotions as complimentary models. Human Communication Research, 27(1), 38-68. http://dx.doi.org/10.1111/j.1468-2958.2001.tb00775.x

Fransen, M. L., Fennis, B. M., Pryun, A. T. H., \& Das, E. (2007). Rest in peace? Brand-induced mortality salience and consumer behavior. Journal of Business Research, 61, 1053-1061. http://dx.doi.org/10.1016/j.jbusres.2007.09.020

Fransen, M. L., Smeesters, D., and Fennis, B. M. (2011). The role of social presence in mortality salience effects. Journal of Business Research, 64, 29-33. http://dx.doi.org/10.1016/j.jbusres.2009.09.016

Glindemann, K. E., Geller, E. S., \& Fortney, J. N. (1999). Self-esteem and alcohol consumption: A study of college drinking behavior in a naturalistic setting. Journal of Alcohol and Drug Education, 45, 60-71.

Greenberg, J., Pyszczynski, T., Solomon, S., Simon, L., \& Breus, M. (1994). Role of consciousness and accessibility of death-related thoughts in mortality salience effects. Journal of Personality and Social Psychology, 67, 627-637. http://dx.doi.org/10.1037//0022-3514.67.4.627 
Greenberg, J., Solomon, S., \& Pyszczynski, T. (1997). Terror management theory of self-esteem and cultural worldviews: Empirical assessments and conceptual refinements. Advances in Experimental Social Psychology, 29, 61-139.

Harmon-Jones, E., Simon, L., Greenberg, J., Pyszczynski, T., Solomon, S., \& McGregor, H. (1997). Terror management theory and self-esteem: Evidence that increased self-esteem reduces mortality salience effects. $\begin{array}{lllll}\text { Journal of Personality and Social Psychology, } & \text { 72(1), }\end{array}$ http://dx.doi.org/10.1016/S0065-2601(08)60016-7

Hingson, R., Heeren, T., Winter, M., \& Wechsler, H. (2005). Magnitude of alcohol-related mortality and morbidity among U.S. college students ages 18-24: Changes from 1998-2001. Annual Review of Public Health, 26, 259-279.

Jessop, D. C., Albery, I. P., Rutter, J., \& Garrod, H. (2008). Understanding the impact of mortality-related health-risk information: A terror management theory perspective. Personality and Social Psychology Bulletin, 34, 951-964

Jessop, D. C., \& Wade, J. (2008). Fear appeals and binge drinking: A terror management theory perspective. British Journal of Health Psychology, 13, 773-788. http://dx.doi.org/10.1348/135910707X272790

Johnston, L. D., O’Malley, P. M., Bachman, J. G., \& Schulenberg, J. E. (2012). Monitoring the Future national survey results on drug use, 1975-2011: Volume II, College students and adults ages 19-50. Ann Arbor: Institute for Social Research, The University of Michigan.

Johnston, K. L., \& White, K. M. (2003). Binge-drinking: A test of the role of group norms in the theory of planned behavior. Psychology and Health, 18, 63-77. http://dx.doi.org/10.1080/0887044021000037835

Keller, P. A. (1999). Converting the unconverted: The effect of inclination and opportunity to discount health-related fear appeals. Journal of Applied Psychology, 84, 403-415. http://dx.doi.org/10.1037//0021-9010.84.3.403

Larimer, M. E., \& Cronce, J. M. (2007). Identification, prevention, and treatment revisited: Individual-focused college drinking prevention strategies 1999-2006. Addictive Behaviors, 32, 2439-2468.

Leventhal, H. (1971). Fear appeals and persuasion differentiation of a motivational construct. American Journal of Public Health and the Nations, 61(6), 1208-1224.

McCormack, A. S., Laybold, A. M., Dickerson-Nelson, J., \& Budd, C. F. (1993). Stress and substance use: Students' attitudes toward alcohol, marijuana, and cocaine. College Student Journal, 27, 215-222.

Miller, W. R., \& Rollnick, S. (2002). Motivational interviewing: Preparing people for change. New York, NY: Guilford Press.

Paek, H., \& Hove, T. (2012). Determinants of underage college student drinking: Implications for four major alcohol reduction strategies. Journal of Health Communication, 17(6), 659-676. http://dx.doi.org/10.1080/10810730.2011.635765

Palmer, R. S., Kilmer, J. R., \& Larimer, M. E. (2006). If you feed them will they come? The use of social marketing to increase interest in attending a college alcohol program. Journal of American College Health, 55, 47-52. http://dx.doi.org/10.3200/JACH.55.1.47-52

Pyszczynski, T., Greenberg, J., \& Solomon S. (1999). A dual-process model of defense against conscious and unconscious death-related thoughts: An extension of terror management theory. Psychological Review, 106, 835-845. http://dx.doi.org/10.1037//0033-295X.106.4.835

Pyszczynski, T., Greenberg, J., Solomon, S., Arndt, J., \& Schimel, J. (2004). Why do people need self-esteem? A theoretical and empirical review. Psychological Bulletin, 130, 435-468. http://dx.doi.org/10.1037/0033-2909.130.3.435

Rogers, R. W. (1983). Cognitive and physiological processes in fear appeals and attitude change: A revised theory of protection motivation, In J. Cacioppo \& R. Petty (Eds.), Social Psychophysiology (153-176). New York: Guilford.

Rosenblatt, A., Greenberg, J., Solomon, S., Pyszczynski, T., \& Lyon, D. (1989). Evidence for terror management theory: I. The effects of mortality salience on reactions to those who violate or uphold cultural values. Journal of Personality and Social Psychology, 57, 681-690. http://dx.doi.org/10.1037//0022-3514.57.4.681 
Roskos-Ewoldsen, D. R., Yu, H. J., \& Rhodes, N. (2004). Fear appeal messages affect accessibility of attitudes toward the threat and adaptive behaviors. Communication Monographs, 71(1), 49-69. http://dx.doi.org/10.1080/0363452042000228559

Routledge, C., Arndt, J., \& Goldenberg, J. L. (2004). A time to tan: Proximal and distal effects of mortality salience on sun exposure intentions. Personality and Social Psychology Bulletin, 30, 1347-1358. http://dx.doi.org/10.1177/0146167204264056

Ruiter, R. A. C., Abraham, C., \& Kok, G. (2001). Scary warnings and rational precautions: A review of the psychology of fear appeals. Psychology and Health, 16, 613-630. http://dx.doi.org/10.1080/08870440108405863

Schmeichel, B. J., Gailliot, M. T., Filardo, E. A., McGregor, I., Gitter, S. \& Baumeister, R. F. (2009). Terror management theory and self-esteem revisited: The roles of implicit and explicit self-esteem in mortality salience effects. Journal of Personality and Social Psychology, 96(5), 1077-1087. http://dx.doi.org/10.1037/a0015091

Shehryar, O., \& Hunt, D. M. (2005). A terror management perspective on the persuasiveness of fear appeals. Journal of Consumer Psychology, 15(4), 275-287. http://dx.doi.org/10.1207/s15327663jcp1504_2

Smith-McLallen, A., Fishbein, M., \& Hornik, B. (2011). Psychosocial determinants of cancer-related information-seeking among cancer patients. Journal of Health Communication, 16, 212-225. http://dx.doi.org/10.1080/10810730.2010.522227

Substance Abuse and Mental Health Services Administration. (2012). Results from the 2011 National Survey on Drug Use and Health: Summary of National Findings, NSDUH Series H-44, HHS Publication No. (SMA) 12-4713. Rockville, MD: Substance Abuse and Mental Health Services Administration.

Taubman Ben-Ari, O., Florian, V., \& Mikulincer, M. (1999). The impact of mortality salience on reckless driving: A test of terror management mechanisms. Journal of Personality and Social Psychology, 76, 35-45.

Thorson, J. A., \& Powell, F. C. (1992). A revised death anxiety scale. Death Studies, 16(6), 507-521. http://dx.doi.org/10.1080/07481189208252595

Treise, D., Wolburg, J. M.,\& Otnes, C. O. (1999). Understanding the "social gifts" of drinking rituals: An alternative framework for PSA developers. Journal of Advertising, 28, 17-31. http://dx.doi.org/10.1080/00913367.1999.10673581

Wechsler, H., Lee, J. E., Kuo, M., Seibring, M., Nelson, T. F., \& Lee, H. (2002). Trends in college binge drinking during a period of increased prevention efforts. Journal of American College Health, 50, 203-217. http://dx.doi.org/10.1080/07448480209595713

Wechsler, H., Molnar, B. E., Davenport, A. E., \& Baer. J. S. (1999). College alcohol use: A full or empty glass? Journal of American College Health, 47, 247-252. http://dx.doi.org/10.1080/07448489909595655

Witte, K., \& Allen, M. (2000). A meta-analysis of fear appeals: Implications for effective public health campaigns. Health Education \& Behavior, 27(5), 591-615. http://dx.doi.org/10.1177/109019810002700506

Witte, K. (1992). Putting the fear back into fear appeals: The extended parallel process model. Communication Monographs, 59, 329-349. http://dx.doi.org/10.1080/03637759209376276

Witte, K. (1994). Fear control and danger control: A test of the extended parallel process model (EPPM). Communication Monographs, 61,113-134. http://dx.doi.org/10.1080/03637759409376328

Wolfson, M., Champion, H., McCoy, T. P., Rhodes, S. D., Ip, E. H., Blocker, J. N., ... DuRant, R.H. (2012). Impact of a randomized campus/community trial to prevent high-risk drinking -among college students. Alcoholism: Clinical and Experimental Research, 36(10), 1767-1778. http://dx.doi.org/10.1111/j.1530-0277.2012.01786.x

Wong, N. C. H., \& Cappella, J. N. (2009). Antismoking threat and efficacy appeals: Effects on smoking cessation intentions for smokers with low and high readiness to quit. Journal of Applied Communication Research, 37(1), 1-20.

\section{(cc)) BY}

This work is licensed under a Creative Commons Attribution 3.0 License. 